\title{
INCLUSION COMPLEX OF GEDUNIN-2-HYDROXYPROPYL-B-CYCLODEXTRIN PREPARED BY KNEADING AND FREEZE-DRYING METHODS: SYNTHESIS AND STRUCTURAL CHARACTERIZATION
}

Mary Olufunmilayo OLOGE ${ }^{1 *}$, Adedibu Clement TELLA ${ }^{2}$, Olubunmi ATOLANI $^{2}$, Olajire Aremu $\mathrm{ADEGOKE}^{3}$, Olusegun George ADEMOWO ${ }^{1,4}$

${ }^{* 1}$ Department of Pharmacology and Therapeutics, P.M.B.1515, University of Ilorin, Ilorin, Nigeria

${ }^{2}$ Department of Chemistry, P.M.B.1515, University of Ilorin, Ilorin, Nigeria

${ }^{3}$ Departments of Pharmaceutical Chemistry, P.M.B.1515, University of Ilorin, Ilorin, Nigeria

${ }^{4}$ Institute for Advanced Medical Research and Training, University of Ibadan, Ibadan, Nigeria

*Correspondence:

Mary Olufunmilayo OLOGE

funmiologe@yahoo.com

Received: 21 May 2021; Accepted: 16 June 2021; Published: 30 June 2021

\begin{abstract}
The potential application of gedunin, a pharmacologically active limonoid, is limited in medicine because it has poor aqueous solubility. This study was aimed at preparation and characterization of an inclusion complex of gedunin and 2-hydroxypropyl- $\beta$-cyclodextrin (HBD) to increase the solubility in aqueous solvents and thus enhance the possibility of pharmaceutical formulation and oral administration of gedunin. Inclusion complex of gedunin isolated from Entandrophragma angolense heartwood with 2hydroxypropyl- $\beta$-cyclodextrin (HBD) was prepared using freeze-drying and kneading methods. The gedunin-2-hydroxypropyl- $\beta$-cyclodextrin complex (GCD) was characterized using elemental analysis, Fourier-transform infrared spectroscopy (FT-IR), ${ }^{1} \mathrm{H}$ nuclear magnetic resonance $\left({ }^{1} \mathrm{H}-\mathrm{NMR}\right)$ and X-ray diffraction analysis (XRD). Elemental analysis indicated that gedunin and HBD formed 1:1 stoichiometric inclusion complex. Results of FT-IR indicated that gedunin was stabilized in HBD cavity by intra-molecular hydrogen bonds and van der Waals forces. ${ }^{1} \mathrm{H}-\mathrm{NMR}$ revealed that the entire gedunin molecule was not trapped into the core of the HBD. Nevertheless, the fraction trapped may be sufficient to enhance the apparent solubility of gedunin. XRD results showed the formation of new solid crystalline phase. The results obtained by different characterization techniques clearly indicated that both kneading and freeze-drying methods led to inclusion complex formation which may enhance oral administration of gedunin.
\end{abstract}

Keywords: Gedunin, 2-hydroxypropyl- $\beta$-cyclodextrin, inclusion complex, spectroscopy.

\section{Introduction}

Cyclodextrins (CDs) are non-toxic macrocyclic biodegradable oligosaccharides which contain at least $6 \mathrm{D}-(+)$ glucopyranose units attached by $\alpha-(1,4)$ glucosidic bonds. They have a relatively hydrophobic central cavity and a hydrophilic outer surface. The CDs and their derivatives have the capability to form non-covalent inclusion complexes both in solution and in solid state with a wide variety of guest molecules of appropriate shape and size (Jansook et al., 2017; Wankar et al., 2020). The most common pharmaceutical application of cyclodextrins is to enhance drug solubility in aqueous solutions (Gowardhane et al., 2014; 
Jambhekar and Breen, 2016). Drug (Omar et al., 2003). Additionally, its short halfbioavailability is expected to improve through enhancement of the solubility and dissolution rate. Cyclodextrins are considered to have advantage over organic solvents as solubilizers, in terms of toxicology and kinetics of solubility enhancement (Stella and He, 2008). Gedunin (Fig. 1.) is a limonoid that is common to the Meliaceae plant family (MacKinnon et al., 1997). This limonoid is potent in vitro against Plasmodium falciparum but it has limited in vivo activity against Plasmodium berghei. This has been partly attributed to poor solubility and low uptake (due to its lipophilicity), first pass metabolism by intestinal cytochrome P-450 enzymes of the small intestines (which reduce its plasma levels) and hydrolysis to its inactive and unstable metabolite, 7-deacetylgedunin life and poor solubility in water have limited its application in medicine.

Complexation with cyclodextrins is expected to ease oral administration of gedunin thus increasing its pharmaceutical applications because the lack of water solubility reduces the flexibility for drug formulation and administration.

2-hydroxypropyl- $\beta$-cyclodextrin

(Fig. 2.) is the most widely used cyclodextrin derivatives in current scientific researches and in the industry because it has excellent inclusion properties for many compounds, is less toxic, safe, and an effective drug carrier (Srivalli and Mishra, 2016; Carneiro et al., 2019). It is mainly used in food, pharmaceutical and cosmetics industries.

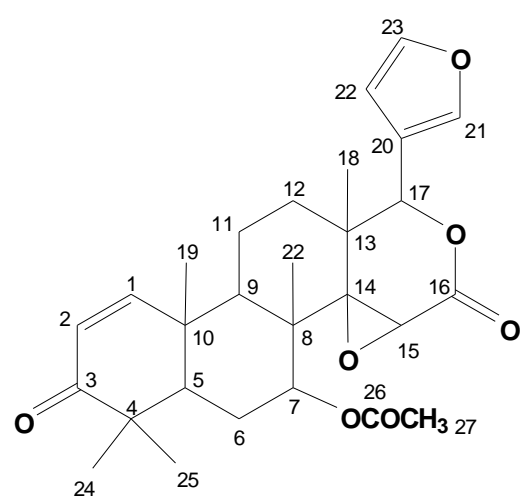

Fig. 1. Gedunin

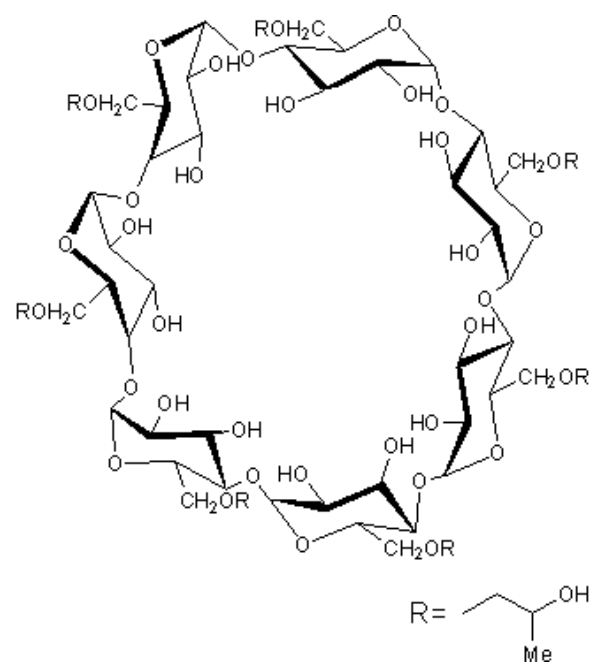

Fig. 2. 2-hydroxypropyl- $\beta$-cyclodextrin (HBD) 
We have previously reported a stoichiometric ratio of $1: 1$ for inclusion complex formation between gedunin and HBD (Ologe et al., 2016). A survey of literature on inclusion complexes revealed that no inclusion complex between gedunin and HBD has been reported to date. In this study, isolation and preparation of gedunin from Entandrophragma angolense Welwitsch C.D.C (Meliaceae) heartwood was carried out and the inclusion complex containing gedunin as guest and HBD as host was prepared by freeze-drying and kneading methods.

\section{Materials and methods}

\subsection{Spectroscopic methods}

All reagents were purchased from SigmaAldrich and were used without further purification. Infra-red spectra were obtained from the samples in the form of potassium bromide (KBr) pellets using FTIR 8400s Spectrometer (Shimadzu, Japan). The analyses of carbon, hydrogen, and nitrogen were carried out on a Perkin-Elmer $240^{\circ} \mathrm{C}$ series elemental analyzer (Germany). For the Nuclear Magnetic Resonance (NMR) experiments, the sample was dissolved in either deuterated DMSO or chloroform and the ${ }^{1} \mathrm{H}-\mathrm{NMR}$ and ${ }^{13} \mathrm{C}-\mathrm{NMR}$ spectra for all samples were recorded at 600 $\mathrm{MHz}$ on Bruker Avance NMR spectrometer (U.S.A). Powder X-ray diffraction (PXRD) patterns were recorded on a scintag PADS diffractometer (Scintag, Santa Clara, CA) using $\mathrm{Cu} \mathrm{K} \alpha$ radiation $(\lambda=1.54059 \AA$, voltage of 40 $\mathrm{kV}$ and $25 \mathrm{~mA}$ current). Each sample was analyzed between 4.0 to $40.0(2 \theta)$ range with a total scan time of $4.0 \mathrm{~min}$.

\subsection{Preparation and Isolation of Gedunin}

Gedunin was isolated from Entandrophragma angolense Welwitsch C.D.C (Meliaceae) heartwood using the modified procedure of Akisanya et al (1961) and Okhale et al (2012). Briefly, 100g of powdered heartwood of $E$. angolense was extracted with $400 \mathrm{ml}$ of $\mathrm{n}$-hexane by solvent extraction at $60^{\circ} \mathrm{C}$ for $48 \mathrm{~h}$. The extract was vacuum filtered with Whatman No. 1 filter paper. The filtrate was concentrated under vacuum with rotary evaporator at $40^{\circ} \mathrm{C}$ to $100 \mathrm{ml}$ and allowed to stand in the dark for $24 \mathrm{~h}$ during which gedunin crystallized out. The isolation of pure gedunin from Crude crystal was done by thin layer chromatography (TLC) using authentic gedunin sample as reference. The crude crystals were further purified by column chromatography, preparative thin layer chromatography (PTLC) and recrystallization with methanol in order to isolate the pure shining white crystals.

Gedunin $\left(\mathrm{C}_{28} \mathrm{H}_{34} \mathrm{O}_{7}\right.$; Fig. 1.): Yield: 0.92 $\%, \mathrm{Mp} .=219^{\circ} \mathrm{C}, \mathrm{M} . \mathrm{wt}=482 \mathrm{~g} / \mathrm{mol}$ Anal. Calc. for $\mathrm{C}_{28} \mathrm{H}_{34} \mathrm{O}_{7}(\%)$ : C, 69.71; H, 7.05; O, 23.24 Found \%: C, 68.71; H, 6.68; O, 20.54; IR(Kbr, $\left.v / \mathrm{cm}^{-1}\right): 2960,1731,1435,1255,1233,1048$, $1024,875,796,698,627,604,400 ; \mathrm{Rf}=0.68$. IR (KBr) $V_{\max }$ : 2960 (C-H Str), $1731(\mathrm{C}=\mathrm{O})$, 1435, 1373 (C=C), 1255 (C-O-C), 1047, 1048 (C-O) $\mathrm{cm}^{-1} ;{ }^{1} \mathrm{H}$ NMR $\left(600 \mathrm{MHz}, \mathrm{CDCl}_{3}\right) \delta$ (ppm) as shown in Table 1 and Figure $2 .{ }^{13} \mathrm{C}$ NMR $\left(\mathrm{CDCl}_{3}\right) \delta$ (ppm): 203.9 (C-3), 169.9 (7acetyl CO), 167.4 (C-16), 156.9 (C-1), 143.1 (C-23), 141.2 (C-21), 126.0 (C-2), 120.4 (C20), 109.8 (C-22), 78.2 (C-17), 73.2 (C-7), 69.7 (C-14), 56.8 (C-15), 44.0 (C-5), 42.6 (C-4), 40.0 (C-8), 39.5 (C-10), 46.0 (C-13), 38.7 (C9), 27.1 (C-24), 26.0 (C-12), 23.2 (C-6), 21.1 (C-19), 21.0 (C-27, 7-acetyl $\left.\mathrm{CH}_{3}\right), 19.7$ (C-25), 18.31 (C-26), 17.7 (C-18), 14.9 (C-11).

\subsection{Preparation of gedunin-2- hydroxypropyl- $\beta$-cyclodextrin complex (GCD)}

The preparation of solid complexes of gedunin and HBD were performed by kneading and freeze-drying methods using a molar ratio of 1:1 based on the results of the stoichiometric ratio determination(Ologe et al., 2016). 


\subsubsection{Kneading method}

The required quantities of gedunin and HBD were weighed accurately in a ratio of $1: 1$. Product from the kneading method was obtained by adding small amount of ethanol: water (1:5) to HBD placed in a glass mortar, the two were mixed to obtain a homogeneous paste. Gedunin was slowly added and the mixture was kneaded for $60 \mathrm{~min}$. During the process, few drops of the ethanol: water was introduced to maintain a suitable consistency. The resulting paste was dried in an oven at 70 ${ }^{0} \mathrm{C}$ for 3 days. The dried complex was pulverized into a fine powder using $100 \mu \mathrm{m}$ mesh sieve.

Yield: $69.6 \%, \mathrm{Mp} .=254^{\circ} \mathrm{C}, \mathrm{M} \cdot \mathrm{wt}=$ 1852g/mol Anal. Calc. for $\mathrm{C}_{82} \mathrm{H}_{132} \quad \mathrm{O}_{46}(\%)$ : C, 53.17; H, 7.1; O, 39.7\% Found \%: C, 52.20; $\mathrm{H}, 6.79$; O,39.52 ; IR (KBr, v/cm $\left.{ }^{-1}\right)$ : 3335br(O$\mathrm{H}), 2936 \mathrm{~m}(\mathrm{C}-\mathrm{H}), \quad 1739(\mathrm{C}=\mathrm{O}), \quad 1668 \mathrm{~m}(\mathrm{H}-\mathrm{O}-\mathrm{H}$ bending), $1457(\mathrm{C}=\mathrm{C}), 1234 \mathrm{~m}(\mathrm{C}-\mathrm{O}-\mathrm{C}), 1025(\mathrm{C}-$ O)

\subsubsection{Freeze-drying method}

The complex was prepared by mixing gedunin and HBD, 1:1 molar ratio using freezedrying method. Equimolar amount of the drug dissolved in $95 \%$ ethanol was added to the HBD in distilled water. The suspension was shaken at $37{ }^{\circ} \mathrm{C}$ for $6 \mathrm{~h}$. The resulting solution was kept in a $-20{ }^{\circ} \mathrm{C}$ freezer and lyophilized in a freeze-dryer (LTE Lyotrap Plus, UK) for 24 h.

Yield: $69.3 \%, \mathrm{Mp} .=255^{\circ} \mathrm{C}, \mathrm{M} \cdot \mathrm{wt}=$ $1852 \mathrm{~g} / \mathrm{mol}$ Anal. Calc. for $\mathrm{C}_{82} \mathrm{H}_{132} \mathrm{O}_{46}(\%)$ : C, 53.17; H, 7.1; O, 39.7\% Found \%: C, 52.23; $\mathrm{H}, 6.89$; O,39.60 ;IR $\left(\mathrm{KBr}, v / \mathrm{cm}^{-1}\right)$ : ;IR $(\mathrm{KBr}$, $\left.v / \mathrm{cm}^{-1}\right): 3330 \mathrm{br}(\mathrm{O}-\mathrm{H}), 2935 \mathrm{~m}(\mathrm{C}-\mathrm{H}), 1737(\mathrm{C}=\mathrm{O})$, $1667 \mathrm{~m}(\mathrm{H}-\mathrm{O}-\mathrm{H}$ bending $), 1457(\mathrm{C}=\mathrm{C}), 1239(\mathrm{C}-$ $\mathrm{O}-\mathrm{C}), 1024 \mathrm{~s}(\mathrm{C}-\mathrm{O})$

\section{Results and discussion}

Gedunin was isolated from the Entandrophragma angolense Welwitsch C.D.C (Meliaceae) heartwood. Elemental analysis, Melting points (Table 1.) and the combined spectra FT-IR (Table 2.), ${ }^{1} \mathrm{H}$ and ${ }^{13} \mathrm{C}$ NMR data of isolated compound conformed with literature reports (Connolly et al., 1967; Taylor, 1974; Hofer et al., 2009) and were used to establish the structure as gedunin $\left(\mathrm{C}_{28} \mathrm{H}_{34} \mathrm{O}_{7}\right)$. The infrared spectrum (Fig. 5a) exhibited peak at strong peak at $1731 \mathrm{~cm}^{-1}$ which corresponds to the carbonyl of the $\alpha, \beta$ - unsaturated ketone of ring $\mathrm{A}$ lactone ring. The broadness of the $\alpha, \beta-$ unsaturated carbonyl was apparently due to the contribution from the carbonyl of the lactone and acetate. The $\beta$-substituted furan ring exhibited peaks at 1435 and $796 \mathrm{~cm}^{-1}$ while the $\mathrm{C}-\mathrm{O}-\mathrm{C}$ of the ether was recorded at 1253 and $1232 \mathrm{~cm}^{-1}$. Putting all the data together, the compound (Fig. 1.) was unambigiously established as tetranortriterpenoid, a special class called limonoid precisely as gedunin or 16,17-Seco-24-nor-5 $\alpha, 13 \alpha, 14 \beta, 17 \alpha$-chola1,20,22-trien-16-oic acid, 14,15ß:21,23diepoxy-7 $\alpha, 17$-dihydroxy-4,4,8-trimethyl-3oxo-16,17-lactone, acetate.

Precisely, the ${ }^{1} \mathrm{H} \quad \mathrm{NMR}$ exhibited resonance at attributable to $\beta$-substituted furan, ring A 1-en-3one, an $\alpha, \beta$ - unsaturated lactone and acetate at C-7 and five tertiary methyl signals which are consistent with the basic structural skeleton of gedunin. The signals at $\mathrm{H}-15$ and H-17 which corresponds to $\delta 3.49$ and $5.58 \mathrm{ppm}$ respectively are additional characteristic signals of gedunin (Ohochuku and Powell, 1966). The relatively downfield shift of the H-17 was apparently due to the coupling with allylic proton of the furan on ring $\mathrm{E}$ while the $\mathrm{H}-15$ with 14,15 - epoxide has no close neighbouring proton for such coupling. Equally, this is partly responsible the more sharp singlet observed for H-15. 
Similarly, five characteristic methyl shifts between $\delta 1.12$ - 1.22 ppm corresponding to $\mathrm{H}$ $18,19,20,24$, and 25 respectively were observed. The ${ }^{13} \mathrm{C}$ NMR data showed (Fig. 2.) distinct 28 signals. Three carbonyls signals at $\delta$ 203.9, 167.4 and 169.9 ppm which corresponded to $\mathrm{C}-3, \mathrm{C}-16$ and $\mathrm{C}-26$ were observed while the other quartenary carbons (C-4, C-8, C-10, C-13, C-14, C-15 and C-20) were all observed as stated $a b$ initio. The epoxide C-14 and C-15 were also distinctly observed at $\delta 69.7$ and $56.8 \mathrm{ppm}$.

Two principal methods were adopted in the preparation of the formulation; kneading and freeze-drying techniques. Thus two products (inclusion complexes) were formed and were characterized using elemental analysis, melting point, FT-IR, ${ }^{1} \mathrm{HNMR}$ spectroscopies and PXRD. The Melting point and \% of $\mathrm{C}, \mathrm{H}$ and $\mathrm{O}$ are given in Table 1. Based on the analytical data and the molecular formula assigned, the complexes revealed 1:1 mole ratio which corresponded well to general formula $\mathrm{C}_{82} \mathrm{H}_{132}$ $\mathrm{O}_{46}$.
The obtained values of the elemental analysis were very much similar to the calculated values and indicate the complexes are fairly pure. The complexes are nonhygroscopic solids with melting points higher than the starting materials. An initial study on behavior of gedunin, HBD and GCD in various solvents showed that gedunin and its complexes had sharp electronic absorption spectra bands in acetate buffer of $\mathrm{pH} 3.50$ (Ologe et al., 2016). This implies that the interaction with an acid allowed for the formation of discrete bonds. The discrete sharp bands imply the complex is not involved in extensive solute-solvent interactions that usually produce band broadening in UV spectrum. The presence of an acidic medium also aids ionization of cyclodextrin due to their basic $\mathrm{pKa}$ values. The formation of very sharp bands between gedunin and HBD in acetate buffer led to the adoption of acetate buffer as the medium for the spectrophotometric titrations of the two compounds as previously reported (Ologe et al., 2016).

Table1. Analytical data of Gedunin and Inclusion complexes synthesized by both methods

\begin{tabular}{|c|c|c|c|c|}
\hline $\begin{array}{l}\text { Gedunin/ } \\
\text { Complexes }\end{array}$ & $\begin{array}{l}\text { Molecular } \\
\text { formula }\end{array}$ & M. wt (g/mol) & $\begin{array}{l}\text { Melting } \\
\text { point }\left({ }^{\circ} \mathrm{C}\right)\end{array}$ & $\begin{array}{l}\mathrm{C} \quad \mathrm{H} \quad \mathrm{O} \\
\% \text { found(calculated) }\end{array}$ \\
\hline Gedunin & $\mathrm{C}_{28} \mathrm{H}_{34} \mathrm{O}_{7}$ & 482.5 & 219 & $\begin{array}{l}\mathrm{C}, 68.71(69.71) \\
\mathrm{H}, 6.68(7.05) \\
\mathrm{O}, 20.54(23.24)\end{array}$ \\
\hline GCD(Kneading) & $\mathrm{C}_{82} \mathrm{H}_{132} \mathrm{O}_{46}$ & 1852 & 254 & $\begin{array}{l}\mathrm{C}, 52.20(53.17) \\
\mathrm{H}, 6.79(7.10) \\
\mathrm{O}, 39.52(39.7)\end{array}$ \\
\hline GCD(Freeze-drying) & $\mathrm{C}_{82} \mathrm{H}_{132} \mathrm{O}_{46}$ & 1852 & 255 & $\begin{array}{l}\mathrm{C}, 52.23(53.17) \\
\mathrm{H}, 6.89(7.10) \\
\mathrm{O}, 39.60(39.7)\end{array}$ \\
\hline
\end{tabular}

\subsection{Infra-red spectra}

Figure 3 shows comparison of the infrared spectra for gedunin, HBD, GCD (kneading) and GCD (freeze-dried). Table 2 shows comparison of the selected FT-IR data of the HBD and inclusion complexes; comparison of selected FT-IR data of gedunin and inclusion complexes is shown in Table 3. The frequencies for gedunin observed at 2960, 1731, 1435, 1255, $1048 \mathrm{~cm}^{-1}$ correspond to $v(\mathrm{C}-\mathrm{H}), \quad v(\mathrm{C}=\mathrm{O}), \quad v(\mathrm{C}=\mathrm{C}), \quad v(\mathrm{C}-\mathrm{OC}), \quad v(\mathrm{C}-\mathrm{O})$ respectively. Meanwhile, the frequencies for 
HBD recorded at 3320, 2928, 1642,1231 , $1022 \mathrm{~cm}^{-1}$ were assigned to $v(\mathrm{O}-\mathrm{H}), v(\mathrm{C}-\mathrm{H})$, $v(\mathrm{H}-\mathrm{OH})$ bending, $v(\mathrm{C}-\mathrm{OC})$ and $v(\mathrm{C}-\mathrm{O})$ respectively. The FT-IR spectra of the GCD inclusion complexes were identical to that of HBD instead of gedunin due to the less amount of gedunin in the complex. This finding was in agreement with the results of other researchers (Subramaniam et al., 2010; Yuan et al., 2012). It can be observed in Table 2 that the bands at 3320 and $2928 \mathrm{~cm}^{-1}$ for pure HBD were shifted to higher wavenumber $\sim 3330$ and 2935 $\mathrm{cm}^{-1}$ for the inclusion complex due to the formation of intramolecular O-H---O hydrogen bonds and presence of van der Waals forces that stabilize gedunin in the cavity of HBD (Sambasevan et al., 2013). The absorption bands at 1435 due to $\mathrm{v}(\mathrm{C}=\mathrm{C})$ in gedunin shifted to higher frequency $\sim 1457 \mathrm{~cm}^{-1}$ for both complexes, in addition $\mathrm{v}(\mathrm{C}=\mathrm{O})$ band at 1731 in gedunin also shifted to higher wavenumber at $\sim 1737 \mathrm{~cm}^{-1}$, this indicates the formation of complex between guest and host. When complexation occurs, the peaks can change position, diminish or even disappear (Corti et al., 2007., Hui et al., 2020 ), thus the disappearance, decreased intensity and change in position of some gedunin absorption bands, in the GCD spectra, point to formation of a complex between the guest and host. The modification of some of the bands representing the guest molecule is indicative that only part of the molecule has been encapsulated by the cyclodextrin. The portion that has not been complexed is responsible for the presence of any unchanged bands (Yang et al., 2008). The presence of two unchanged bands $(\mathrm{C}=\mathrm{O}$ and $\mathrm{C}=\mathrm{C}$ ) in the kneading and freeze-dried complex shows that the gedunin molecule is not totally encapsulated in HBD. This is in line with the NMR analysis.

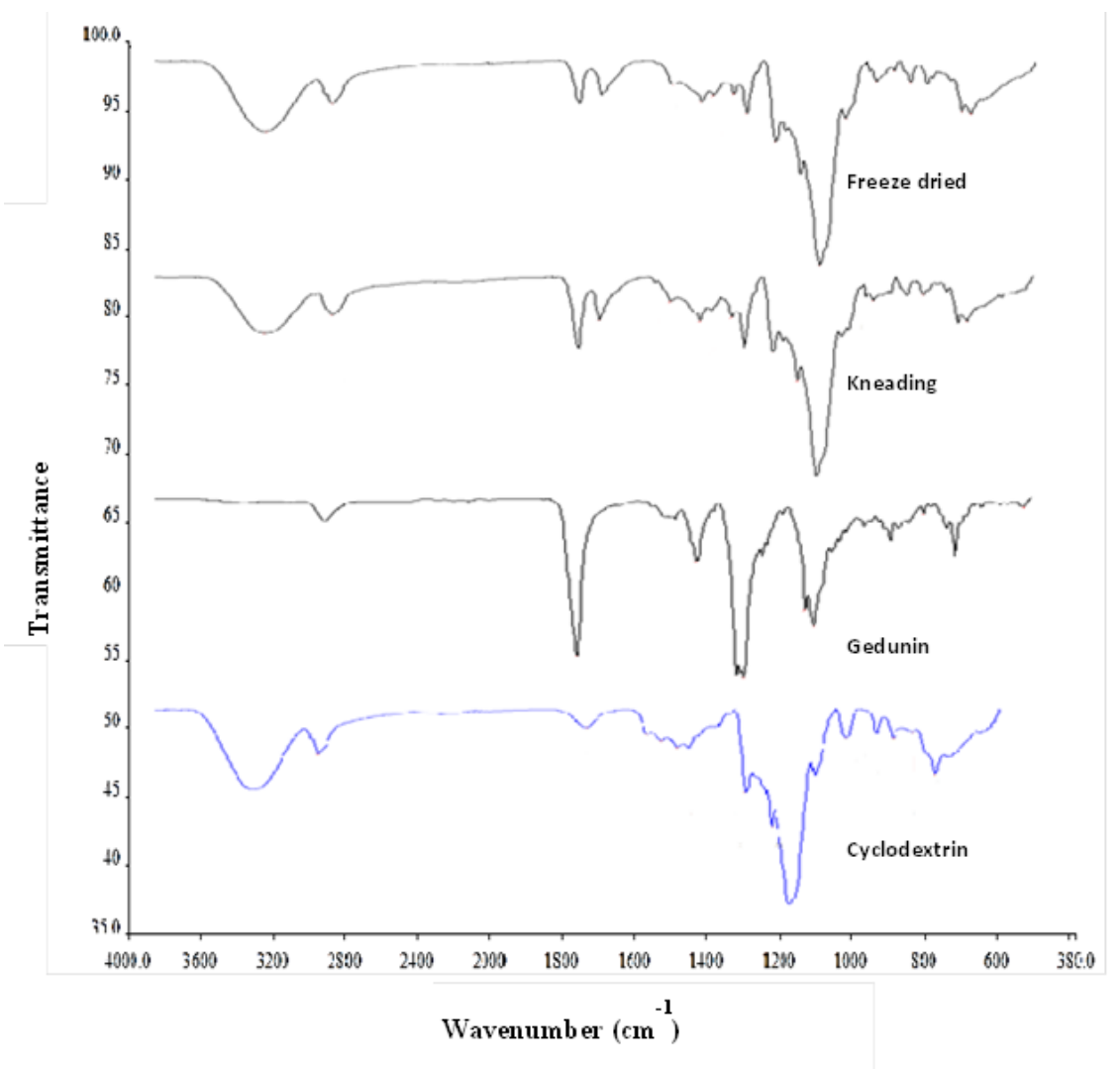

Fig. 3. Infrared spectra of 2-hydroxypropyl-cyclodextrin (HBD), gedunin, GCD (kneading), GCD (freeze-dried) 
Table 2. Comparison between FT-IR spectra of HBD and Inclusion complexes (kneading and freeze-dried)

\begin{tabular}{llll}
\hline Functional group & HBD & $\begin{array}{l}\text { Inclusion complex } \\
\text { (Kneading) }\end{array}$ & $\begin{array}{l}\text { Inclusion complex } \\
\text { (Freeze- dried ) }\end{array}$ \\
\hline$v(\mathrm{OH})$ & $3320 \mathrm{br}$ & 3335 & $3330 \mathrm{br}$ \\
$v(\mathrm{C}-\mathrm{H})$ & 2928 & $2936 \mathrm{~m}$ & $2935 \mathrm{~m}$ \\
$v(\mathrm{H}-\mathrm{O}-\mathrm{H})$ & $1643 \mathrm{~s}$ & $1668 \mathrm{~s}$ & $1667 \mathrm{~s}$ \\
$\begin{array}{l}\text { bending } \\
v(\mathrm{C}-\mathrm{OC})\end{array}$ & $1231 \mathrm{~s}$ & $1234 \mathrm{~s}$ & $1239 \mathrm{~s}$ \\
$v(\mathrm{C}-\mathrm{O})$ & $1022 \mathrm{~s}$ & $1025 \mathrm{~m}$ & $1024 \mathrm{~m}$ \\
\hline
\end{tabular}

Note: $\mathrm{br}=$ broad, $\mathrm{m}=$ medium, $\mathrm{s}=$ strong, $\mathrm{w}=$ weak

Table 3. Comparison between FT-IR spectra of Gedunin and Inclusion complexes (kneading and freeze-dried)

\begin{tabular}{llll}
\hline Functional group & Gedunin & $\begin{array}{l}\text { Inclusion } \\
\text { complex } \\
\text { (Kneading) }\end{array}$ & $\begin{array}{l}\text { Inclusion } \\
\text { complex } \\
\text { (Freeze- dried ) }\end{array}$ \\
\hline $\mathrm{V}(\mathrm{O}-\mathrm{H})$ & - & $3335 \mathrm{br}$ & $3330 \mathrm{br}$ \\
$\mathrm{V}(\mathrm{C}-\mathrm{H})$ & $2960 \mathrm{w}$ & $2936 \mathrm{~m}$ & $2935 \mathrm{~m}$ \\
$\mathrm{~V}(\mathrm{C}=\mathrm{O})$ & $1731 \mathrm{~s}$ & $1739 \mathrm{~m}$ & $1737 \mathrm{~m}$ \\
$\mathrm{~V}(\mathrm{C}=\mathrm{C})$ & $1435 \mathrm{~m}$ & $1457 \mathrm{~m}$ & $1457 \mathrm{~m}$ \\
$\mathrm{~V}(\mathrm{C}-\mathrm{OC})$ & $1255 \mathrm{~s}$ & $1234 \mathrm{~s}$ & $1239 \mathrm{~s}$ \\
$\mathrm{~V}(\mathrm{C}-\mathrm{O})$ & $1048 \mathrm{~s}$ & $1025 \mathrm{~m}$ & $1024 \mathrm{~m}$ \\
\hline
\end{tabular}

Note: $\mathrm{br}=$ broad, $\mathrm{m}=$ medium, $\mathrm{s}=$ strong, $\mathrm{w}=$ weak

\subsection{NMR Spectra}

In order to study the principal structural changes occurring in the gedunin molecule, the ${ }^{1} \mathrm{H}$ and ${ }^{13} \mathrm{C}$ NMR spectra (Fig. 4.) were recorded. In addition, the ${ }^{1} \mathrm{H}-\mathrm{NMR}$ spectra of both the kneaded and freeze-dried products were recorded (Fig. 5.). Table 4 shows the proton signals for gedunin, kneaded and freezedried complex with HBD. NMR spectroscopy has been widely used to investigate cyclodextrin inclusion complexes (Floury et al., 2016). A cursory look at the differences between the major protons of complexed gedunin relative to that of the intact gedunin shows similar magnitude between the proton signals. However, looking at the intensities of the signals for the freeze-dried sample and considering that the kneaded samples (Fig. 5.) were prepared in the same mole fraction as the freeze-dried, the latter had all proton signals with higher intensities than the kneaded samples. From Table 4, it is also evident there is not much difference in the proton signals of both the kneaded and freeze-dried products. From the columns on the subtraction of the chemical shift values from that of intact gedunin, very similar differences were produced in the signals obtained for both formulated products. Very close values were particularly obtained for protons on carbon numbers 4, 8, 18 and 22.

Some of the protons experienced a significant shielding effect in which the proton signals obtained for the complex had lower chemical shifts values compared to gedunin alone. This implies that such protons must be within the core of the complex and those exposed to the outside were found to be deshielded (i.e. possessing higher chemical shift values than the intact gedunin moiety). 


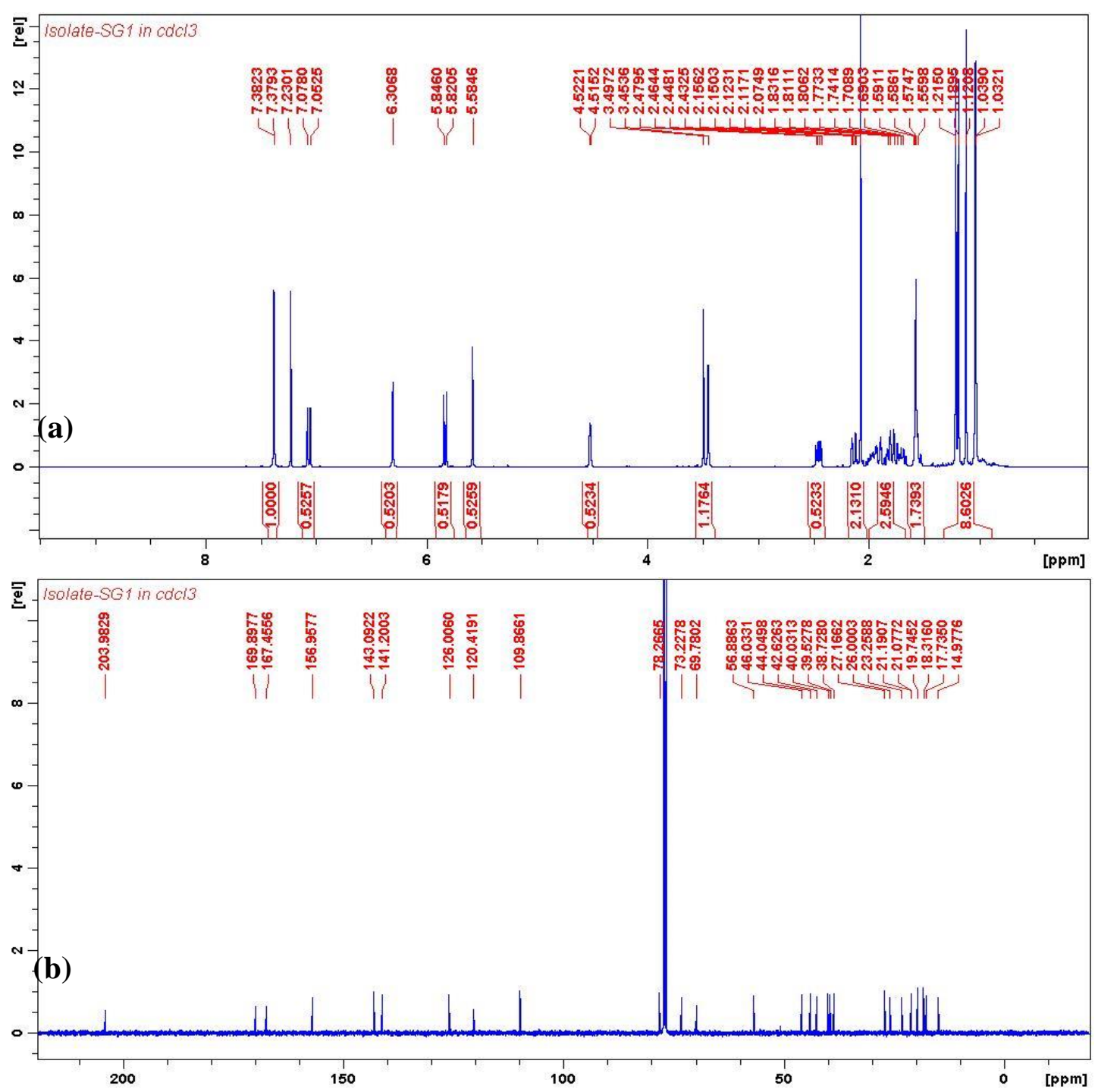

Fig. 4. (a) ${ }^{1} \mathrm{H}$ NMR and (b) ${ }^{13} \mathrm{C}$ NMR for gedunin in deuterated Chloroform

Shielding implies that the protons are held in a more magnetically enriched environment and hence a stronger amount of energy is required to bring them into resonance. Functional groups within the gedunin molecule that is involved in the binding of gedunin through hydrophobic interaction in the interior of the HBD molecule will shield the protons from the environment generating low chemical shift values.

From Table 4, some of the protons that experienced shielding are those on Ring A (proton numbers 2 and 4); Ring B (protons numbers 5, 6, 8 and 9); Ring C (proton numbers 11, 12 and 13) and Ring $\mathrm{E}$ (proton number 19). A small shielding effect was observed for proton number 18 on ring $\mathrm{D}$ with the freeze-dried product was which actually deshielded in the kneaded proton, this thus appears insignificant for the consideration of the complex formation. This is the evidence of the guest inclusion in the cyclodextrin cavity (Schneider et al., 1998; Shah et al., 2010). Some of the protons experiencing deshielding are notably those near the few mildly polar functional groups and thus these may be at the outer portion of the cyclodextrin. The classical protons that seem to point to the positioning of the gedunin in the hydrophobic core of the complex are those on Rings A and B as well as proton 19 on Ring E. 


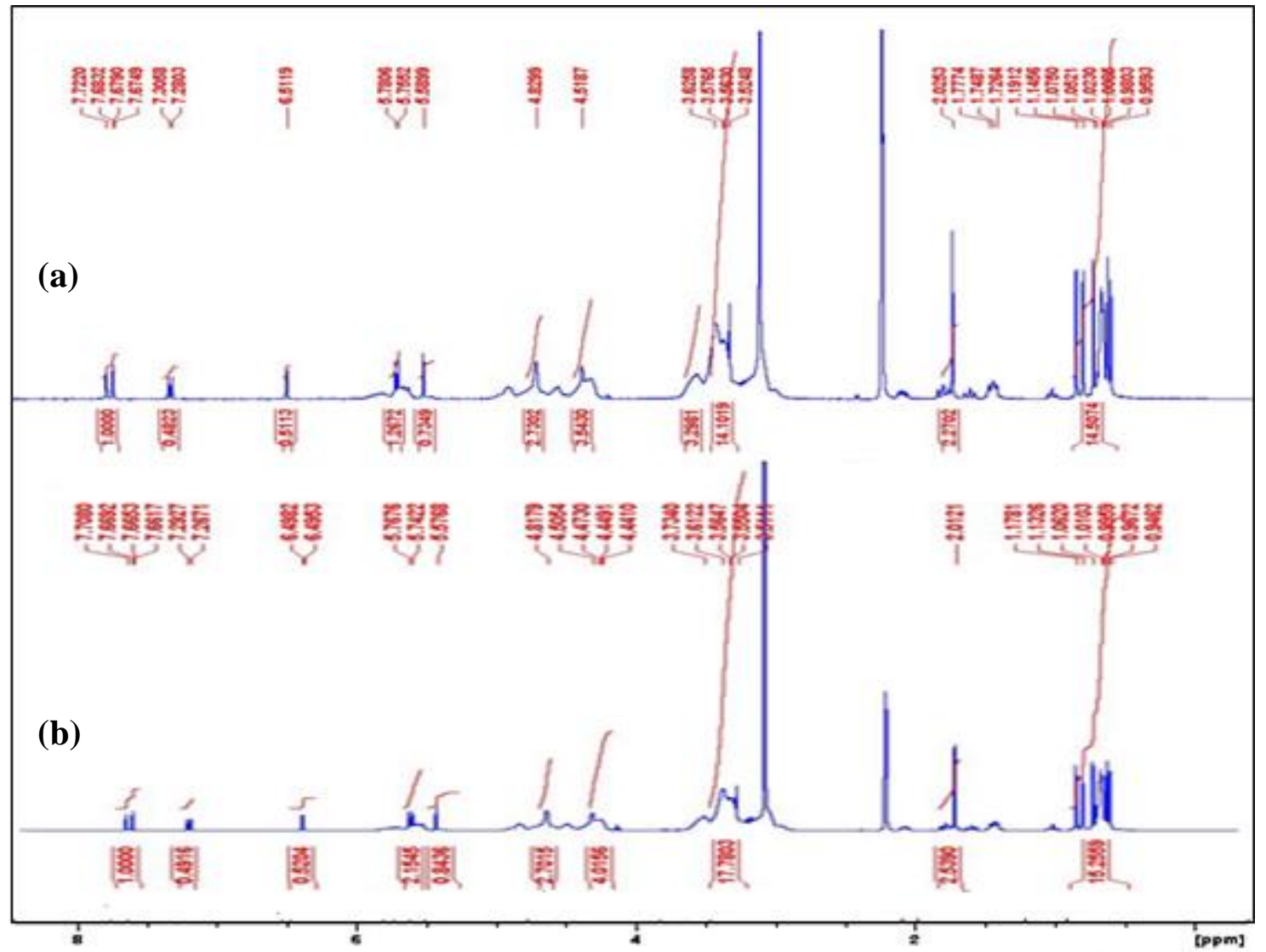

Fig. 5. ${ }^{1} \mathrm{H}$ NMR spectrum for GCD prepared by (a) kneading method; (b) freeze-dried method

There thus seem to a conformation that permit the Rings A and B and part of Ring E to be positioned in the core of HBD while Rings $\mathrm{C}$ and $\mathrm{D}$ are at the outer region alongside the remaining portions of Ring $E$. The few exceptions to this submission are those protons on Ring $\mathrm{C}$ (C-11) which experienced slight shielding especially the axial protons and the C-13 methyl protons which are also out of plane with the ring. The positioning of these two protons may actually contribute to their being shielded when the molecule undergoes a twisting to fit into the hydrophobic core of HBD.

In summary, the presence of shielded protons has justified the formation of an inclusion complex between HBD and gedunin and the observance of deshielded protons points to the idea that not the entire gedunin molecule is trapped into the core of the complex (Cabral and Pugh., 1990; Celin and
Nagarajan., 2014). Nevertheless, the fraction trapped may be sufficient to enhance the apparent solubility of gedunin. Biopharmaceutics Classification System (BCS) is a scientific tool used for classifying drugs based on their aqueous solubility and intestinal permeability characteristics. In general, formulation techniques that increase aqueous solubility of Class II and Class IV drugs without decreasing their lipophilicity will enhance their absorption through biological membranes (Loftsson et al., 2005). Gedunin can be regarded as a class II (low solubility and high permeability) compound on the BCS because of its lipophilicity. Thus, the complexation between gedunin and HBD should have a positive effect on the absorption of gedunin after oral administration. 
Mary Olufunmilayo Ologe et al.

Table 4. Proton Chemical Shifts values for GCD compared with gedunin alone

\begin{tabular}{|c|c|c|c|c|c|}
\hline $\mathrm{C} / \mathrm{H}$ no. & $\delta\left({ }^{\mathrm{I}} \mathrm{H}\right)-$ Gedunin & $\begin{array}{l}\delta\left({ }^{\mathrm{I}} \mathrm{H}\right)-\mathrm{GCD} \\
\text { (Kneaded) }\end{array}$ & $\begin{array}{l}\delta\left({ }^{\mathrm{I}} \mathrm{H}\right)-\mathrm{GCD} \\
\text { (Freeze dried) }\end{array}$ & $\begin{array}{l}\text { Difference } \\
\text { between } \delta \text { of } \\
\text { gedunin and } \\
\text { GCD } \\
\text { (Kneaded)* }\end{array}$ & $\begin{array}{l}\text { Difference } \\
\text { between } \delta \text { of } \\
\text { gedunin and } \\
\text { GCD (Freeze- } \\
\text { dried)* }\end{array}$ \\
\hline \multicolumn{6}{|l|}{ Ring A } \\
\hline 1 & $7.065(1 \mathrm{H}, d)$ & Not detected & Not detected & & \\
\hline 2 & $5.8333(1 \mathrm{H}, \mathrm{dd})$ & $5.7679(\mathrm{~d}, J=10.16 \mathrm{~Hz})$ & $5.7549(\mathrm{~d}, J=10.16 \mathrm{~Hz})$ & +0.0654 & +0.0784 \\
\hline \multicolumn{6}{|l|}{3} \\
\hline 4(methyl groups) & $1.2224(6 \mathrm{H})$ & 1.0521 & 1.0620 & +0.1703 & +0.1604 \\
\hline \multicolumn{6}{|l|}{ Ring B } \\
\hline 5 & $\begin{array}{l}1.2335(1 \mathrm{H}) \\
1.54-1.566(2 \mathrm{H})\end{array}$ & $\begin{array}{l}1.0750 \\
1.1456 \\
\end{array}$ & $\begin{array}{l}1.0620 \\
1.1326 \\
\end{array}$ & $\begin{array}{l}+1.1585 \\
+0.4204 \\
\end{array}$ & $\begin{array}{l}+0.1715 \\
+0.4334 \\
\end{array}$ \\
\hline $\begin{array}{l}6 \text { (methyl group on acetyl } \\
\text { substituent) }\end{array}$ & $2.0820(3 \mathrm{H})$ & 2.0253 & 2.0121 & +0.0567 & +0.0699 \\
\hline 6 & $3.48(1 \mathrm{H})$ & 3.5725 & 3.5111 & -0.0925 & -0.0311 \\
\hline 7 (Methyl group - endocyclic) & $1.1279(3 \mathrm{H})$ & 1.1456 & 1.1326 & -0.0177 & -0.0047 \\
\hline 8 (endocyclic) & $1.5405(1 \mathrm{H})$ & 1.1912 & 1.1781 & +0.3493 & +0.3624 \\
\hline 9 (methyl group) & $1.2335(3 \mathrm{H})$ & 1.0750 & 1.0620 & +0.1585 & +0.1715 \\
\hline 10 & $1.5988(1 \mathrm{H})$ & 1.7508 & Not detected & -0.152 & - \\
\hline \multicolumn{6}{|l|}{ Ring C } \\
\hline 11 & $\begin{array}{l}1.2335 \text { (Axial) } \\
1.5660 \text { (Equatorial) }[2 \mathrm{H}]\end{array}$ & $\begin{array}{l}1.0750 \\
1.7508 \\
\end{array}$ & $\begin{array}{l}1.0620 \\
\text { Not detected }\end{array}$ & $\begin{array}{l}+0.1585 \\
-0.1848 \\
\end{array}$ & $\begin{array}{l}+0.1715 \\
- \\
\end{array}$ \\
\hline 12 & $\begin{array}{l}1.2335 \text { (Axial) } \\
1.5405 \text { (Equatorial) }[2 \mathrm{H}]\end{array}$ & $\begin{array}{l}1.0750 \\
1.7508 \\
\end{array}$ & 1.0620 & $\begin{array}{l}+0.1585 \\
-0.2103 \\
\end{array}$ & +0.1715 \\
\hline 13 & & & Not detected & & - \\
\hline C-13 methyl group & $1.1279(3 \mathrm{H})-$ methyl protons & 1.0750 & 1.0620 & +0.0529 & +0.0659 \\
\hline \multicolumn{6}{|l|}{ Ring D } \\
\hline \multicolumn{6}{|l|}{14} \\
\hline 15 & $3.4972(1 \mathrm{H}, s)$ & 3.6258 & 3.6122 & -0.1286 & -0.1150 \\
\hline \multicolumn{6}{|l|}{16} \\
\hline 17 & $5.5846(1 \mathrm{H}, \mathrm{s})$ & 5.5899 & 5.5768 & -0.0053 & +0.0078 \\
\hline Ring E & & & & & \\
\hline
\end{tabular}


ABMJ 2021, 4(1): 83-97

\begin{tabular}{|c|c|c|c|c|c|}
\hline 19 & $7.3808(1 \mathrm{H}, \mathrm{d})$ & $7.2931(d, J=10.2 \mathrm{~Hz})$ & $7.2799(\mathrm{~d}, J=10.24 \mathrm{~Hz})$ & +0.0877 & +0.1009 \\
\hline 20 & $6.3068(1 \mathrm{H}, \mathrm{s})$ & $6.5119(s)$ & $\begin{array}{l}6.4968 \\
\text { (weak splitting, } J=1.16 \mathrm{~Hz} \text { ) }\end{array}$ & -0.2051 & -0.91 \\
\hline \multicolumn{6}{|c|}{$\begin{array}{llll}1 & 0\end{array}$} \\
\hline 22 & $7.0653(1 \mathrm{H}, d d)$ & $\begin{array}{l}7.6898 \\
(d d, J=18.84 \text { and } 1.68 \mathrm{~Hz})\end{array}$ & $\begin{array}{l}7.6761 \\
(d d, J=18.52 \text { and } 1.56 \mathrm{~Hz})\end{array}$ & -0.6245 & -0.6108 \\
\hline 18 (methyl) & $1.1279(3 \mathrm{H}) \mathrm{CH}_{3}$ & 1.0750 & 1.0620 & +0.0529 & +0.0659 \\
\hline 19 & $1.2335(3 \mathrm{H})$ & 1.0750 & 1.0620 & +0.1585 & +0.1715 \\
\hline 20 (methyl)-endocyclic) & $1.1279(3 \mathrm{H})$ & 1.1456 & 1.1326 & -0.0177 & -0.0047 \\
\hline 24,25(2-methyl group) & $1.2224(6 \mathrm{H})$ & 1.0521 & 1.0620 & +0.1703 & +0.1604 \\
\hline $26,27\left(\mathrm{OCOCH}_{3}\right)$ & $2.0820(3 \mathrm{H})$ & 2.0253 & 2.0253 & +0.0567 & +0.0699 \\
\hline
\end{tabular}

Note: ${ }^{a}$ Integrals in parenthesis; $s=$ singlet; $d=$ doublet; $d d=$ doublet of doublet; *positive sign (proton shielded relative to gedunin), negative sign denotes deshielding 


\subsection{Powder X-ray diffraction (PXRD)}

Figure 6 shows the PXRD patterns of gedunin, HBD and GCD obtained via kneading and freeze-drying. Gedunin displayed some distinct peaks at $2 \theta=6.98,12.40,18.85,24.78$, 25.58 and 27.71 which are absent in GCD due to complexation. The PXRD diffraction patterns of the complexes are completely different from starting materials. New diffraction peaks in the spectrum and the shift of the representative guest molecule peaks as well as the changes in their relative intensity confirm the formation of a new solid phase and complexation (Mura, 2015). Quantitative estimation of the $2 \theta$ PXRD patterns of GCD (kneading) and GCD (freeze-dried) revealed that the major peaks in the PXRD patterns of GCD (kneading) were observed at $2 \theta=5.64$, $6.22,8.22,10.48,12.37,12.99,13.71,14.44$, $15.44,16.15,17.11,18.66,20.57$ and 21.11 while those of GCD (freeze-dried) were observed at $2 \theta=5.73,6.17,8.34,10.38,10.55$, $12.33,12.87,13.69,14.31,15.49,16.44,17.06$, 18.42, 20.64 and 21.16.

Powder X-ray diffractometry is an appropriate procedure for establishing the molecular state of an inclusion complex (Singh et al., 2010). The closeness of $2 \theta$ values for GCD prepared by the different method in the PXRD analysis strongly implies that the two methods (freeze-drying and kneading) produced similar complexes.

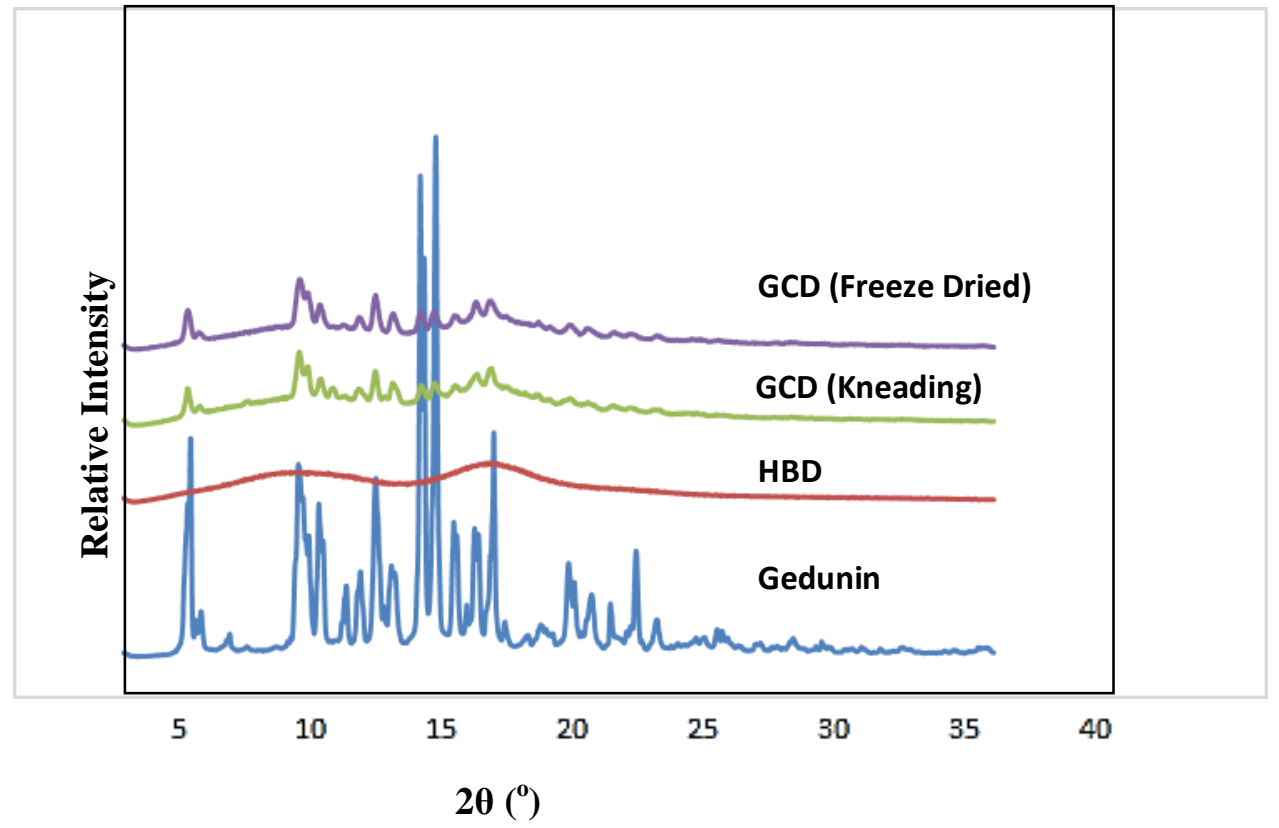

Fig. 6. Powder X-ray diffraction patterns of Gedunin, HBD, GCD (kneading) and GCD (freeze-dried)

\subsection{Comparison of the methods (Kneading and Freeze-drying methods)}

The two methods had almost the same yield of $\sim 69 \%$. The freeze-drying method was completed within a shorter time of about $30 \mathrm{hrs}$ as compared to kneading method which took 3 days to get the product. In addition, the freezedrying may be a better method for the preparation of the inclusion complex since the proton signals of the freeze-dried complex had higher intensities. (Veiga et al., 2001; Shah et al., 2010). 


\section{Conclusions}

Pure Gedunin was successfully isolated and characterized to ascertain its structure. The inclusion complex of gedunin (GED) and 2hydroxypropyl- $\beta$-cyclodextrin (HBD) was prepared using kneading and freeze-dried methods. The complexes were characterized using elemental analysis, FT-IR, ${ }^{1} \mathrm{H}$ NMR and PXRD. These characterization methods support inclusion complex formation. The entire gedunin molecule was not trapped in the cyclodextrin cavity but the partial entrapment may be sufficient to improve the aqueous solubility of the complexes thus increasing possibility of pharmaceutical formulation and oral administration of gedunin. The studies revealed that freeze-dried method presents higher efficiency in terms of shorter time of preparation compared to kneading method especially for large scale industrial production. This makes the complexes potential therapeutic agents suitable for subsequent applications.

\section{Acknowledgement}

Author appreciates the Staff Development Award from University of Ilorin, Ilorin, Nigeria which led to the execution of part of the study.

\section{Conflict of interest}

The authors declare that the research was conducted in the absence of any commercial or financial relationships that could be construed as a potential conflict of interest.

\section{References}

1. Akisanya A, Bevan CW, Halsall TG. Powell JW, Taylor DAH (1961) West African Timbers, Part IV, Some Reactions of Gedunin. J Chem Soc 3705-3708.

2. Cabral Marques HM, Pugh WJ (1990) Studies of cyclodextrin inclusion complexes II. Molecular modeling and ${ }^{1} \mathrm{H}$ NMR evidence for the salbutamol- $\beta$ cyclodextrin complex. International Journal of Pharmaceutics. 63(3): 267-274.

3. Carneiro SB, Costa Duarte FI, Heimfarth L, et al. (2019). Cyclodextrin-drug inclusion complexes: in vivo and in vitroapproaches. Int J Mol Sci 20:642.

4. Celin TS, Nagarajan S (2014) Inclusion complexation of 2-aminopyrimidines with $\beta$-cyclodextrin, physico-chemical and nuclear magnetics spectroscopic studies. Materials Science-Poland 32(1): 39-44.

5. Connolly JD, McCrindle R, Overton KH, Warnock WDC (1967) Tetranortriterpe noids- III; 6-Hydroxy and 6-acetoxy-methyl angolensate from heartwood of Khaya grandifoliola. Tetrahedron 23: 4035 - 4039.

6. Corti G, Capasso G, Maestrelli F, Cirri M, Mura P (2007) Physical-chemical characterization of binary systems of metformin hydrochloride with triacetyl- $\beta$ cyclodextrin. J Pharm Biomed Anal 45: 480-486.

7. Floury M, Landy D, Ruellan S, Auezova L, Greige-Gerges H, Fourmentin S (2016) Determination of formation constants and structural characterization of cyclodextrin inclusion complexes with two phenolic isomers: carvacrol and thymol. Beilstein $\mathbf{J}$ Org Chem 12: 29-42. doi:10.3762/bjoc.12.5

8. Gowardhane AP, Kadam NV, Dutta S (2014) Review on Enhancement of Solubilization Process. American Journal of Drug Discovery and Development 4: 134152.

9. Hofer M, Greger H, Mereiter K (2009) 6 $\alpha$ Acetoxygedunin. Organic compounds, Acta Crystallographica Section E. E65, o1942o1943.

10. Hui BY, Zain NNM, Mohamad S, Prabu S, Osman H, Raoov M (2020) A comprehensive molecular insight into host- 
guest interaction of Phenanthrene with native and ionic liquid modified $\beta$-cyclo dextrins: Preparation and characterization in aqueous medium and solid state, Journal of Molecular Structure 1206: 127675. https://doi.org/10.1016/j.molstruc.2019.127 675.

11. Jambhekar SS, Breen P. Cyclodextrins in pharmaceutical formulations II: solubilization, binding constant, and complexation efficiency (2016) Drug Discovery Today 21(2): 363-368. doi.org/10.1016/j.drudis.2015.11.016.

12. Jansook P, Ogawa N, Loftsson T (2017) Cyclodextrins: Structure, physicochemical properties and pharmaceutical applications. International Journal of Pharmaceutics 535: 272-284.

13. Loftsson $T$, Jarho $P$, Masson $M$, Jarvinen $T$ (2005) Cyclodextrins in Drug Delivery. Expert Opinion on Drug Delivery 2(2): 335 - 351.

14. MacKinnon S, Durst $T$, Arnason JT, Angerhofer C, Pezzuto JM, SanchezVindas PE, Poveda LJ, Gbeassor FM (1997) Antimalarial activity of Tropical Meliaceae extracts and Gedunin Derivatives. Journal of Natural Products 60: 336-341.

15. Mura P (2015) Analytical techniques for characterization of cyclodextrin complexes in the solid state: a review. Journal of Pharmaceutical and Biomedical Analysis 113(10): 226-238. http://doi.org/10.1016/j.jpba.2015.01.058.

16. Ohochuku NS, Powell JW (1966) Nuclear Magnetic Resonance Spectroscopy, The Bandwidths of the Singlets in Gedunin and its Simple Derivatives. Chemical communications London 13: 422-423.

17. Okhale SE, Amupitan JO, Ndukwe IG, Oladosu PO, Okogun JI (2012) Synthetic modification of gedunin and comparative antibacterial activity of gedunin and 7- deacetoxy-7 $\alpha$-hydroxygedunin potassium salt. African Journal of Pure and Applied Chemistry 6(14):183-189.

18. Ologe MO, Adegoke AO, Iwalewa EO, Ademowo OG (2016) Spectrophotometric studies of a novel Gedunin-2-Hydroxypro pyl- $\beta$-cyclodextrin binary complex. African Journal of Medicine and Medical Sciences 45:159-169.

19. Omar S, Zhang J, MacKinnon S, Leaman D, Durst T, Philogene BJR, Arnason JT, Sanchez-Vindas PE, Poveda L, Tamez PA, Pezzuto JM (2003) Traditionally Used Antimalarials from the Meliaceae. Current Topics in Medicinal Chemistry 3: 133-139.

20. Sambasevan KP, Mohamad S, Sarih NP, Ismail NA (2013) Synthesis and Characterization of the inclusion Complex of $\beta$-Cyclodextrin and Azomethine. Int $\mathbf{J}$ Mol Sci 14: 3671-3682.

21. Schneider HJ, Hacket F, Rüdiger V, Ikeda H (1998) NMR studies of cyclodextrins and cyclodextrin complexes. Chemical Reviews 98(5): 1755-1785.

22. Shah MR, Sancheti PP, Vyas VK, Karekar PS, Pore YV (2010) Proton magnetic resonance ( $\left.{ }^{1} \mathrm{HNMR}\right)$ spectroscopy and Physicochemical studies of Zaleplonhydroxylpropyl- $\beta$-Cyclodextrin inclusion compounds. Drug discoveries and Therapeutics 4(2): 70 -76.

23. Singh R, Bharti N, Madan J, Hiremath SN (2010) Characterization of Cyclodextrin Inclusion Complexes - A Review. Journal of Pharmaceutical Science and Technology. 2(3): 171-183.

24. Srivalli KM, Mishra B (2016) Improved aqueous solubility and antihyperchole sterolemic activity of ezetimibe on formulating with hydroxypropyl- $\beta$ cyclodextrin and hydrophilic auxiliary substances. AAPS PharmSciTech 17:27283. 
25. Stella VJ, He Q (2008) Cyclodextrins. Toxicologic Pathology 36 (1):30-42.

26. Subramaniam, P, Mohamad S, Alias Y (2010) Synthesis and Characterization of the inclusion Complex Dicationic Ionic Liquid and $\beta$-Cyclodextrin. Int $\mathbf{J}$ Mol Sci 11: $3675-3685$.

27. Taylor DAH (1974) 13C nuclear magnetic resonance spectra of some limonoids. Part I. The structure of procerin, an extractive from Carapa procera. J Chem Soc Perkin Trans 1: 437-441.

28. Veiga F, Fernandes C, Maincent P (2001) Influence of the preparation method on the Physicochemical properties of Tolbutamide/Cyclodextrin binary systems. Drug development and Industrial pharmacy 27(6): 523- 532.

29. Yang X, Ke W, Zi P, Liu F, Yu L (2008) Detecting and identifying the complexation of nimodipine with hydroxypropyl- $\beta$ cyclodextrin present in tablets by Raman spectroscopy. J Pharm Sci 97: 2702-2719.

30. Wankar J, Kotla NG, Gera S, Rasala S, Pandit A, Rochev YA (2020) Recent Advances in Host-Guest Self-Assembled Cyclodextrin Carriers: Implications for Responsive Drug Delivery and Biomedical Engineering. Advanced Functional Materials 30: 1909049 (1-27).

31. Yuan C, Jin ZY, Xu XM (2012) Inclusion complex with hydroxylpropyl- $\beta$ cyclodextrin: UV, FTIR, 1HNMR and molecular modeling studies. Carbohydrate Polymers 89(2): 492-496. 